\title{
Is pneumonectomy mandatory after transection of the left main pulmonary artery?
}

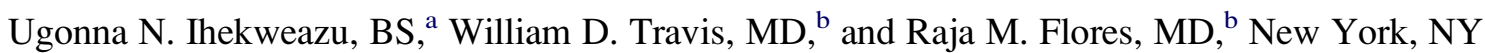

Transection of the main pulmonary artery (PA) is thought to be associated with necrosis of the lung, subsequent sepsis, and death. We report the management of a patient from an outside hospital who underwent an aborted pneumonectomy after transection of the left main PA. We eventually treated the patient with an intrapericardial pneumonectomy. However, the patient was always clinically well, and after pneumonectomy, pathology did not reveal signs of significant necrosis. Therefore, it is possible that a ligated PA is compatible with life.

\section{CLINICAL SUMMARY}

A 44-year-old woman presented to an outside hospital with a large squamous cell carcinoma occluding the left mainstem bronchus. Results of mediastinoscopy and bone scanning were negative for metastasis.

At thoracotomy, the left main PA was completely divided distal to the ligamentum arteriosum (Figure 1). However, on further inspection of the pulmonary veins (PVs) and left atrium, the tumor was deemed unresectable. The thoracotomy was closed, and then the patient was left intubated and transferred to our institution.

Two days later, the patient was extubated. She was hemodynamically stable without evidence of sepsis, hypoxemia,

From the Division of Thoracic Surgery, ${ }^{a}$ Weill Cornell Medical College, and the Division of Thoracic Surgery, ${ }^{\mathrm{b}}$ Memorial Sloan-Kettering Cancer Center, New York, NY.

Disclosures: None.

Received for publication June 30, 2009; revisions received July 28, 2009; accepted for publication Aug 2, 2009; available ahead of print Sept 27, 2009.

Address for reprints: Raja M. Flores, MD, Thoracic Service, Department of Surgery,

Memorial Sloan-Kettering Cancer Center, 1275 York Ave, Room C-879, New

York, NY 10021 (E-mail: floresr@mskcc.org).

J Thorac Cardiovasc Surg 2010;140:242-3

$0022-5223 / \$ 36.00$

Copyright $@ 2010$ by The American Association for Thoracic Surgery

doi:10.1016/j.jtcvs.2009.08.014 or dyspnea. Results of positron emission tomographic scanning and magnetic resonance imaging of the brain were both negative.

Fifteen days after left PA ligation, we performed a reoperative left intrapericardial pneumonectomy. Bronchoscopy revealed complete occlusion of the left upper lobe bronchus by tumor. After removal of the sixth rib, the lung was completely mobilized. Bronchial arteries were intact but were no larger than normal, and no aberrant blood vessels to the left lung were visualized. After transection of the mainstem bronchus, a portion of the left atrium was divided with adequate margins. Pathology revealed a viable lung with no signs of marked necrosis or abscess formation (Figure 2).

The patient is doing well 1 year postoperatively without evidence of disease.

\section{DISCUSSION}

This case illustrates the importance of comprehensive inspection of all structures before attempts at resection. In this regard the tumor invading the left atrium and PVs would have been considered unresectable, and transection of the patient's PA at the initial operation might have been avoided. Interestingly, division of the PA did not lead to significant lung necrosis, sepsis, dyspnea, or hypoxemia. After extubation, the patient was in satisfactory condition. In the short-term, we are able to conclude that despite a transected PA, the patient was clinically well.

In the long-term, we believe that development of collateral circulation from the bronchial arteries or backflow of oxygenated blood from the right lung through the left atrium and left PVs might be sufficient to sustain the lung tissue. In a dog study conducted more than 50 years ago, Liebow and
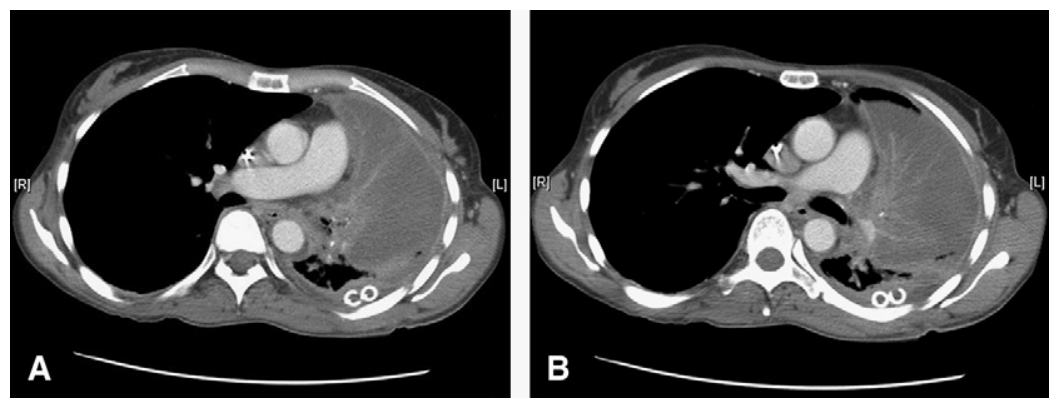

FIGURE 1. A, CT scan of the transected pulmonary artery with lung in place. B, One image cut lower. 

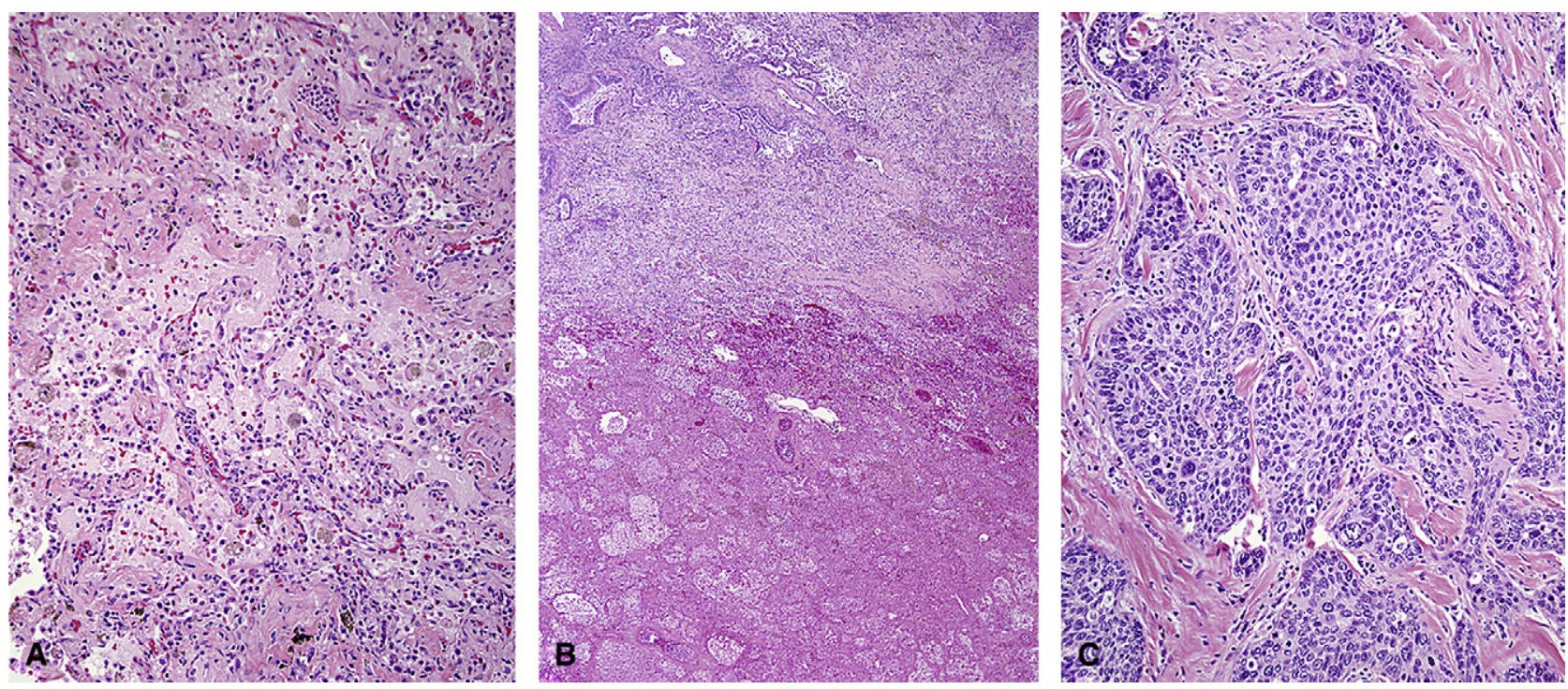

FIGURE 2. A, Normal lung parenchyma with a few alveolar macrophages. B, Focal acute and organizing infarct. C, Squamous cell carcinoma with tumor cells infiltrating the fibrous stroma.

associates ${ }^{1}$ determined that after PA ligation, a compensatory expansion in bronchial circulation exists. Within 12 weeks, bronchial arteries in the terminal bronchi develop cross-sectional areas that are larger relative to PAs at the same level, and thus resistance to blood flow in the lungs remains low. ${ }^{1,2}$ Additionally, it was determined that the location of PA ligation is significant and that a "rough correlation" can be made between the extent of compensatory recirculation and life expectancy. ${ }^{1}$ However, in this patient there would not have been sufficient time for collateral development. Therefore we hypothesize that the lung remained viable because of retrograde travel of oxygenated blood through the left PVs.

Alternatively, studies on infantile pigs found that the amount of alveoli in the involved lung increased rapidly 2 weeks after PA ligation. ${ }^{3}$
This case represents a scenario that might not occur in all instances in which the PA is divided without pneumonectomy. Transection of the left main PA without completing the pneumonectomy does not appear to be harmful in the short-term. In any case this should not be interpreted as an option for pneumonectomy bailouts, and a thorough inspection of all structures before attempts at resection is strongly advised.

\section{References}

1. Liebow AA, Hales MR, Bloomer WE, Harrison W, Lindskog GE. Studies on the lung after ligation of the pulmonary artery. Am J Pathol. 1950;26:177-95.

2. Schlaepfer K. Ligation of the pulmonary artery of one lung with and without resection of the phrenic nerve: experimental study. Arch Surg. 1924;9:25-94.

3. Haworth SG, McKenzie SA, Fitzpatrick ML. Alveolar development after ligation of left pulmonary artery. Thorax. 1981;36:938-43. 